\title{
14q11.2 microdeletion syndrome
}

INSERM

\section{Source}

INSERM. (1999). Orphanet: an online rare disease and orphan drug data base. 14911.2 microdeletion syndrome. ORPHA:261120

14q11.2 microdeletion syndrome is a recently described syndrome characterized by developmental delay, hypotonia and facial dysmorphism. 